\title{
"Giz Negro e Gouache: Egon Schiele"
}

\section{Ênio Squeff}

Willy Corrêa de Oliveira acaba de compor mais uma peça - a valsa "Giz Negro e Gouache: Egon Schiele". Não é a única no gênero composta por ele e é bem possível (e desejável) que não seja a derradeira. Falo em tese. Existem artistas cuja produção é tão mais prolífica quanto mais se despojam do mundo. Não sei se, a rigor, é o caso do Willy. Certa vez, ele me disse que a dedicação de alguns artistas a uma grande produção podia se dar por causas alheias à sua vontade. Falava da produção de alguns amigos comuns e da sua própria. Tentei entender a reflexão e só pude concluir que não se configura, realmente, da responsabilidade dele ou de outros artistas, principalmente do dito Terceiro Mundo, quetenha acontecido o fracasso do socialismo real. Ou seja, o tempo roubado da projeção da utopia teria servidoà arte brasileira como uma espécie de catarsis. Autopia, de qualquer modo, resistiria mas desta vez na arte - de onde, aliás, nunca saiu.

É uma hipótese e ela explicaria a fase de fertilidade não só do compositor Willy Corrêa, mas também do pensador, do crítico, do intėlectual, enfim. Muito mais do que conjeturas, porém, há a realidade concreta tanto da valsa - um gênero universal, mas decisivamente entranhado na história da nossa música; e da dedicatória que, no caso de Willy, nunca é apenas uma menção sem o quê nem porquê. A referência a Egon Schiele, pintor austríaco morto em 1918, aos 28 anos, parece, portanto, muito significativa.

$\mathrm{Na}$ verdade, não vejo vertentes mais importantes para algumas ilações a propósito desta composição. Começa pela valsa. A história do gênero parece ter poucos paralelos na história da música ocidental. A dificuldade da localização da data exata do seu surgimento (equase todos os gêneros musicais são, como os pictóricos, rigorosamente indatáveis) remete a questão para muitos caminhos. Em princípio, a valsa teria 
começado como gesto. Isto a relacionaria com todo um mundo e todo um processo cultural. Por outro lado, conquanto quase todos concordem com a origem etimológica da valsa - que teria a ver com volvere, do latim, isto é, volver, retroceder, rodar -, é na Alemanha e na Áustria que o gênero encontraria sua forma waltz, valse, no francês, ou valsa, no português. Com outras palavras: seria na prática gestual da dança que ela se imporia como gênero aqui e acolá. Mas a própria multifacetação etnológica da dança em si teria colaborado para a sua universalidade e, por via de conseqüência, para a sua ambivalência. Berlioz parece ter atentado para essa incrível característica do gênero, ao anotar que, ao contrário do juízo da maior parte de seus contemporâneos, as maravilhosas valsas de Johann Strauss ostentavam um ressaibo de melancolia que, hoje, todos concordam existir nas peças do "rei da valsa"; e que elas o sensibilizavam exatamente por isso. Certamente teria opiniões diferentes sobre as valsas de Chopin, Liszt, Mozart, Beethoven ou Schubert. Dito de outra forma: existiriam tantos tipos de valsas quanto os compositores e - por que não? - tantas valsas quanto o caráter dos povos que as dançam. Diz-se, aliás, do velho Confúcio, a frase segundo a qual só os povos livres sabem dançar. A ser verdade, as valsas de Dvorak teriam contribuído com seu quinhão para o surgimento da Tchecoslováquia; e as de Ernesto Nazaré, com não menos para o fortalecimento da jovem República Brasileira.

São ilações, digamos, precipitadas. E talvez fosse o caso de se discutir qual a contribuição do gênero, com seus três por quatro ou seis por oito, para a emancipação de algumas civilizações ou países. Ou, por outra: talvez se pudesse escrever sobre a perda de nossa identidade ou mesmo da decadência do nosso futebol (só como exemplo), a partir de uma tese mais ou menos semelhante: ela acusaria na nossa atual indiferença em relação ao samba, o começo de todo o resto. Mas, por aí (e por menos que se aceitem tais teses), não estaríamos muito longe da problemática lançada pela valsa de Willy Corrêa de Oliveira. E examiná-la sob este prisma poderia ser bem mais do que um indício de sua atual fase criativa.

Pode-se voltar à homenagem a Egon Schiele. Eduard Hanslick, o todo poderoso crítico austríaco, odiado por Wagner (que paradoxal- 
mente o imortalizou como personagem do vilão dos "Mestres Cantores'), em seu livro Sobre o Belo na Música, defende o que hoje já não nos parece tão óbvio: de que a música, como arte dos sons, não tinha rigorosamente sentido algum "além daquele que lhe imprimia a fantasia do compositor". Hanslick, ao que parece, tinha razões de sobra para a ressalva. Desde os primeiros românticos insistia-se em que a música queria dizer muito mais do que a filosofia (era esse o aforismo de Beethoven). Schumann chegou a insistir com Mendelssohn de que era capaz de saber exatamente quais os termos dos "poemas" subjacentes a qualquer composição da época. O romantismo parece ter levado a exageros inauditos a reflexão de Hegel que, na sua Estética, afirmaria ser a música "a última instância da subjetividade". Grosso modo, porém, por ser o romantismo um movimento fundamentalmente musical (havia um certo consenso quanto a isto, inclusive de parte de artistas de outras áreas como Delacroix, Heine e alguns mais), no século XIX assistiu-se a toda uma tendência de "musicalização do mundo". Daí, porém, à literalização da música ou à sua conceitualização seria apenas uma questão de enfoque. Assim, Berlioz, Liszt eMahler se baseariam em textos literários para compor muitas de suas peças sinfônicas. E a "Pastoral", apesar das objeções de Beethoven de que não fazia "pintura", não deixaria, em última análise, de ser o mote perfeito para as tentativas de transformar a música em expressão plástica que, num processo descritivo extremado, encontraria nos "Quadros de uma Exposição", de Moussorgsky, um de seus exemplos mais vulgarizados.

Ora, a música nãoé, de fato, literatura; mesmo levando-se em conta as reflexões quase sempre "musicais" de Adorno, ela nãoé, igualmente, filosofia. Mas só para ficar numa constatação, a música é reflexo, expressão e, obviamente, sintoma de seu mundo.

Da geração de Willy Corrêa de Oliveira podem-se, sob este aspecto, fazer algumas extrapolações, como por exemplo, a que foi aquela que viu na realidade da experiência de um regime socialista, na URSS, a possibilidade da abertura da utopia na história, que, no Brasil, foi tanto a geração que sofreu a repressão da ditadura militar, como a que conviveu com o fim da repressão sexual, eé, enfim, a geração que assiste agora ao nascimento do neobarbarismo, tendo como principais protago- 
Revista Música, São Paulo, v.4, n.2: 219-227 nov. 1993

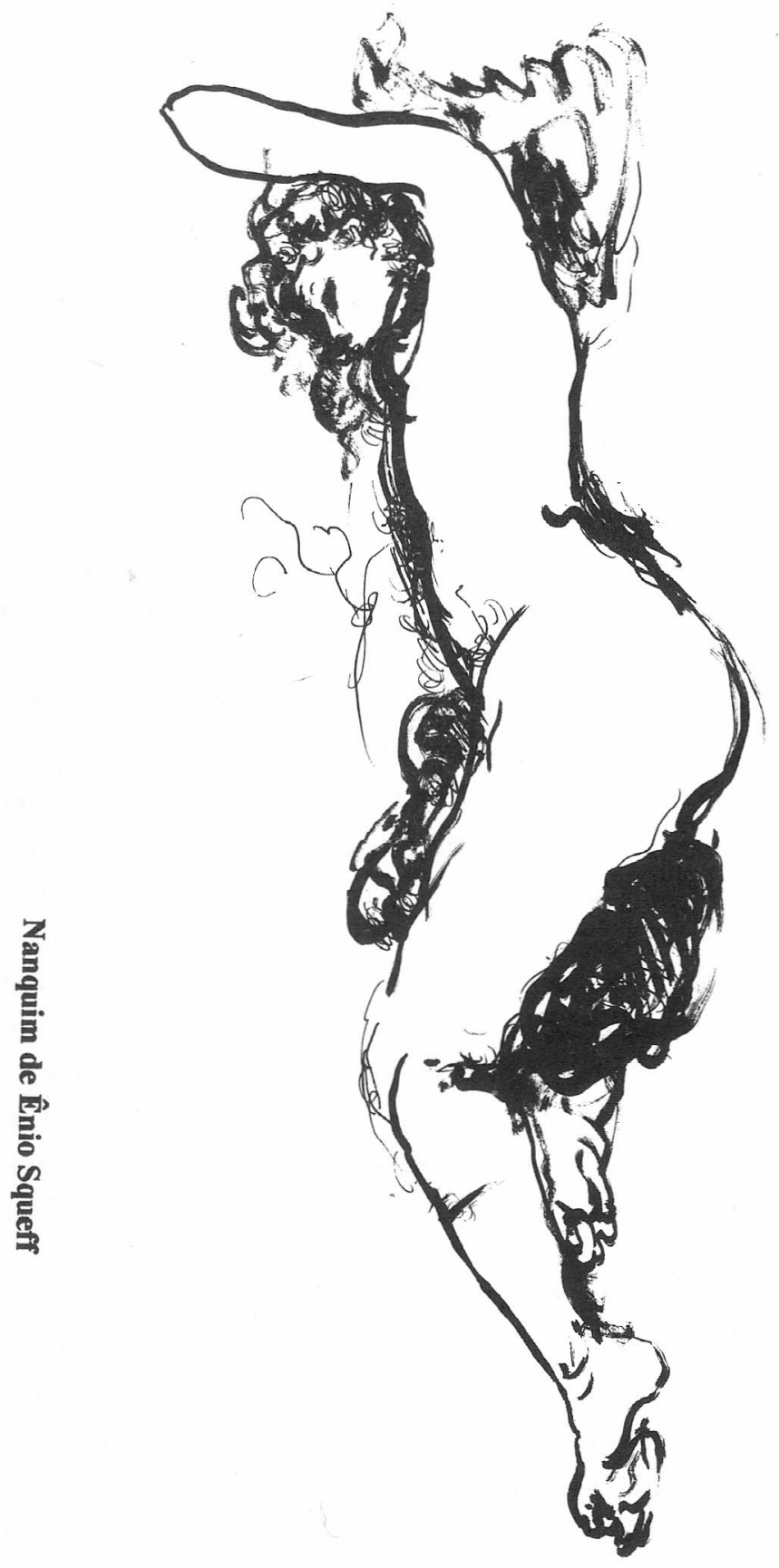


nistas desse auto-holocausto justamente os países que se embalaram no sonho socialista. Ou seja, da geração de Willy, de Gilberto Mendes ou deOlivier Toni (que, no fundo, coma diferença de algunsanos, étambém a minha), se pode dizer, dentre outros, que viveu três momentos distintos em nosso século: a esperança da utopia, a realidade da repressão fascista e, por fim, a vitória do neoliberalismo maltusiano, tendo agora, como situação concreta, a existência do "Big Brother" em carne e osso, representado na hegemonia atômica e sobretudo cultural dos países do capitalismo avançado.

Que dizer disso tudo, tendo em vista o historicismo imbricado, primeiro, na vanguarda serialista e, logo em seguida, na tentativa, por fim escancarada, de uma arte engajada ou pelo menos voltada para a realidade de um país pobre? Que dizer desta arte e deste povo (refirome, claro, ao povo brasileiro), hoje esmagado por uma elite cujo sonho, nomomento, éser ameaçada, não pelos bandidos cariocas(ou paulistanos), mas pelos marginais de Miami Beach (ou Bitch)?

A valsa de Willy talvez se relacione em parte com algumas dessas questões. Anoto que a alusão a Egon Schiele não deixa de ser a dos tempos gloriosos da primeira vanguarda - mas não se furta, igualmente, aos momentos angustiantes de antes do nascimento do socialismo. Lembre-se, a este respeito, que 1918 é o ano Um do socialismo; mas é também o ano da morte de Schiele e de Debussy. Não parece ser por acaso que o período que vai da data do falecimento de Wagner ao início da Primeira Guerra seja permeado por um decadentismo assumido. $\mathrm{O}$ brasileiro Euclides da Cunha, auto-intitulado "grego tapuia", desde os cafundós de um país em vias de industrialização, clamará sobre um conceito de progresso que esmagará milhares de pessoas em Canudos. Euclides não foi um decadentista, mas anteviu no otimismo do progresso científico estribado no capitalismo triunfante, um dos lados negativos, não assumidos, de uma desumanidade universalmente aceita. Não será sem ironia que dirá estar o Brasil "condenado ao progresso". $\mathrm{Na}$ Europa, porém, tanto pela música de Mahler (que anuncia o fim de uma era), quanto pela pintura, seja de Egon Schiele, seja de seu colega Klimt (apenas para citar dois austríacos). Será através da música conscientemente historicista de Mahler que o romantismo acabará sebultado. 
Assim, o que para alguns (como Adolfo Salazar) se constituía em monstruosidades sinfônicas, para o futuro, em suas constantes citações, ressumava verdadeiros panegíricos fúnebres a uma sociedade que, nem três anos depois da morte de Mahler, iria desaparecer sob os escombros da Primeira Guerra.

Sabe-se o quanto da música historicista de Mahler frutificará ao longo do tempo. No diatonismo aparentemente anacrônico de sua música, feita de citações, menções, aparatos tragicômicos, pastiches ao operismo italiano (muitas vezes escondidos nos laendler), ou em suas incontáveis redundâncias claramente estrondosas, Mahler animará o salto adiante de Schoenberg e de sua escola. Aliás, e a propósito, Mesmo a "Sagração", de Stravinsky, pode ser vista como parte desse decadentismo. Nada como a estetização da barbárie primitiva para contrapô-la à barbárie dos tempos modernos.

Egon Schiele talvez não tenha muito do decadentismo historicista e, portanto, crítico, de Mahler. Se há algo que o distingue de seus contemporâneos pintores é o realismo cru, o erotismo escrachado de suas mulheres, claramente expostas à contemplação voyeurística. Mas Schiele foi também um decadentista à sua maneira, um quase intuitivo. Seria então, por aí - como realidade do próprio tempo antevisto por Schiele, no fim da repressão sexual - a razão da hommage de Willy ao artista? É possível. No filme "Excesso de Punição", sobre o qual se baseia em parte a menção ao pintor (e que se pretende uma biografia filmada de Schiele), o climaé estemesmo. Poreledesfilaum sem-número de mulheres em alusões eróticas pouco menos que explícitas - do lesbianismo à masturbação e desta ao exibicionismo. Sem rebuços, é um pouco o ambiente da valsa.

Assim, a recomendação "lento" com a indicação :120 refere-se, ao que parece, a um dos aspectos do gênero: aquele que permite uma elasticidade de andamento, claramente por sua adequação ao corpo. Valsas supõem meneios de corpos, atividades fisicas que são, em muito, o processo de "incorporação" que preside, por exemplo, aos ritos afrobrasileiros (embora neles, tanto a música quanto a gestualidade sejam, precipuamente, a corporificação do "santo"). A polivalência do gênero, porém, permite outras conclusões. Assim, expressões como "melancó- 
lico", "triste" ou "trágico" têmagora, a ampará-las, não ummero dado subjetivo, tão caro ao romantismo, mas toda uma cultura musical que se reporta em grande parte à tradição austríaca e alemã. Refiro-me especificamente a uma memória musical também histórica. Será dela, mais uma vez, que a criação de Willy, me parece, se fará caudatária. Mahler dizia, a propósito, que os pássaros cantavam mal, referia-se, evidentemente, à inexistência de um projeto historicista no canto dos pássaros. É o que avalisa, em parte, os conceitos até mesmo de morbidez sensual neste trabalho do compositor brasileiro.

O início da valsa se dá com um desenho em saltos de sétima, entremeados por apojaturas. É uma das idéias-força cuja referência às valsas tradicionais pode ser lida tanto como alusão à tradição do gênero, quanto a essa visão crítica do historicismo. É no "teneramente", porém, quando um desenho descendente da mão esquerda lembra o concerto número 24, em dó menor, de Mozart, que a valsa se inicia como tal. E será, por fim, com o movimento já em três por quatro, com novas mençõesaos ornamentos-quesãotambémpróprios dasvalsas chopinianas - que a peça irá se firmar como gênero até uma espécie de autodiluição, num movimento de terças paralelas em quartinas e sextilhas que marcharão em sentido oposto ao de um desenho semelhante, construido para a mão esquerda. É quando o clima trágico assomará em sua plenitude como que a explicar toda a obra. O desenho da melodia que começa com lá natural (num acorde de Fá Maior, em segunda inversão) irá assim evoluir e já como uma espécie de "final fatídico" (se esta for a expressão correta). Ainequivoca citação de Schumanndo "Carnaval" op. 9, é um pouco esse caráter tragicamente remissivo (Cf. Quasi maestoso, pg. 5 - Mesto, pg. 6) e que culminará, por fim (e quase como decorrência "natural"), na referência direta ao trecho "Ziemlich Langsam", do terceiro movimento da Primeira Sinfonia de Mahler (Cf. $d=58$ quasi $-d=69$ circa, pg. 6).

Não cabem maiores extrapolações, a não ser as que a própria música sugere. A curta existência de Schiele, a trágica perseguição a que foi submetido pelas autoridades judiciais da Áustria (sob a acusação de "obscenidade") impõem-se, sob muitos aspectos, como um paradigma à existência mesma. Em Schiele, tanto eros quanto tanathos evoluem 
como o velho jogo entre o feminino e o pecado. É um pouco a esse mito que se refere a peça de Willy. Mas há o peso histórico do gênero, que não sendo escapista como tal, jamais aludirá aos desvalidos (que também a dançarão), muito menos aos malditos, os desviantes de todas as épocas, muitos dos quais não ficaram infensos a seu encanto (basta lembrar o próprio Mahler: Alma Mahler conta que ele apreciava dançar valsas).

Em uma palavra: para uma geração que lidou o tempo inteiro também com os elementos extramusicais - tais como a torcida do "Santos FootballMusic", de Gilberto Mendes ou as menções quea todo o momento se imiscuem na música do próprio Willy Corrêa de Oliveira - "Giz Negro e Gouache: Egon Schiele" é bem indicativa de um novo momento na arte brasileira (ainda que não o único, nem o exclusivo). Agora talvez já não caibam tergiversações sobre os suportes. O que eu quero dizer é que a música é possível ainda enquanto só música. À fase heróica da vanguarda, que redundará numa quase renúncia à música (ocioso aludir aos numerosos compositores dos anos 60 que atualmente já não produzem mais nada), segue-se, pelo que se conclui da produção de Willy, que a música histórica, a grande música, não está morta. Foi, a propósito, esta a idéia que parece ter legado Cláudio Santoro pouco antes de falecer: ele insistia em que não precisava mais "ser moderno para ser eterno". Ao afirmar que gostaria de fazer melodia "como Puccini" (foi o que disse a João Marcos Coelho numa entrevista na Folha), Santoro parecia perseguir de novo e sempre, tão somente a música, "a doce música". Não parece menos o que a geração - mais uma vez "órfã da utopia" - proclamará estoicamente. Concluindo, não obstante a vitória da indústria cultural, a indiscutível hegemonia do capitalismo, há ainda a resistência quase bizantina. Mas, atualmente, de uma arte que não mais espera se afirmar "não-arte", para reivindicar seu estatuto no mundo.

Fazer música ou conservar o princípio dela em sua integridade, ainda que num horizonte de referências de um mundo alienado de si próprio, talvez seja apenas e tão somente preciso. Já que (quem sabe?) viver - de novo - não é preciso. Mas é assim, tem que ser assim; pelo menos é o que nos sugere essa valsa, ou melhor, essa idéia de valsa que Willy nos apresenta. 
E ia concluindo, por fim, esta resenha, sob a promessa íntima de manter a olímpica posição cartesiana de não me derramar em elogios, quem sabe suspeitos, por serem elogios: mas não me parece demasiado exumar a velha palavra beleza para definir este trabalho.

Ênio Squeff é Artista Plástico, Ensaista e Crítico de Arte. 